\title{
Evaluation of rheological performance of a local modified bitumen by Styrene Butadiene Styrene polymer used in wearing course
}

\author{
Kebaili Nabil \\ Departement of Civil Engineering and Hydraulic, Faculty of applied sciences, University Kasdi Merbah of Ouargla, 30000, Algeria \\ kebailinabil69@gmail.com, bttps://orcid.org/0000-0001-6176-8919 \\ Mohamed Djouhri \\ Laboratory of Exploitation and Valorization of Natural Resources in Arid Areas (EVRNZA), University of Kasdi Merbah, \\ Ouargla, 30000, Algeria \\ m.djoubri@yahoo.fr
}

Mohammed Boucherba

Public Works Laboratory of the South, Ghardaïa, 47000, Algeria

boucherbamohammed@yahoo.fr

Mustapha Kebaili

Departement of Civil Engineering and Hydraulic, Faculty of applied sciences, University Kasdi Merbah of Ouargla, 30000, Algeria m_kebaili@yahoo.fr

ABSTRACT. In road construction, bitumen is the binder that gathers the different aggregates of road pavements. Bitumen, as a viscoelastic material, influences considerably the rheological behavior of bitumen concrete.

The bitumen used in Algeria, shows its limits in facing the traffic, which is increasing continuously. This research aims to valorize Styrene-ButadieneStyrene SBS polymer in wearing course by modifying a pure 35/50 bitumen. The present paper aims to study the polymer derived from styrene and butadiene (SBS) the company Kraton Polymers International Ltd for the modification of a bitumen to improve its mechanical characteristics.

To this end, the incorporation of SBS polymer was carried out according to two contents: 5.0 and $7.5 \%$ (by weight of asphalt) to evaluate the influence of this type of polymer on the rheological properties of the bitumen ordinary road including viscosity and modulus.

The results revealed that the bitumen modified with $7.5 \%$ of SBS has better mechanical performance on the rigidity and the elasticity compared to the conventional bitumen.

Recommendations have been made to implement a bitumen modification system to improve its quality and therefore the durability of bituminous pavements in the south of Algeria.

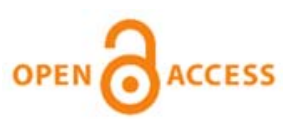

Citation: Nabil, K., Djouhri, M., Boucherba, M., Kebaili, M., Evaluation of rheological performance of a local modified bitumen by Styrene Butadiene Styrene polymer used in wearing course, Frattura ed Integrità Strutturale, 58 (2021) 65-76.

Received: 20.03.2021

Accepted: 19.06 .2021

Published: 01.07.2021

Copyright: (C) 2021 This is an open access article under the terms of the CC-BY 4.0, which permits unrestricted use, distribution, and reproduction in any medium, provided the original author and source are credited. 
KEYWORDS. Polymer modified bitumen; Rigidity; SBS polymer; Thermal susceptibility; Dynamic mechanical analysis.

\section{INTRODUCTION}

A ccording to the European specification, bitumen is defined as a virtually nonvolatile, adhesive, and waterproofing material [1]; Bitumen consists of viscous liquid, essentially made of mineral oil, hydrocarbon derivatives (such as asphaltenes, maltines), which are soluble in carbon di-sulphide, it is considerably non-volatile, and it gradually softens by heating. It is either black or brown in color $[2,3,4]$ and its chemical structure, which depends on its origin and mode of derivation is not fully known [5].

Bituminous binders are widely used by the paving industry $[2,6,3,7]$ as currently produced in the various refineries, and they have limits in terms of mechanical performance necessary to withstand the constantly growing loads under the effect of heavy traffic [8,9]. This constraint requires Algeria and other countries in the region to use bitumen improvement techniques. Types of bitumen used in hot regions, such as the southern Algeria region, are also subject to severe climatic constraints. Indeed, the road sections located in southern Algeria, where a hot and dry climate prevails in summer, are not spared from these obstacles, which represent another challenge that is added to the limits of the bitumen previously reported (Fig. 1). In Algeria, the traditional pure grade 35/50 bitumen used as a wearing course is relatively hard and rigid, which shortens its service life and affects its sensitivity to high summer temperatures.

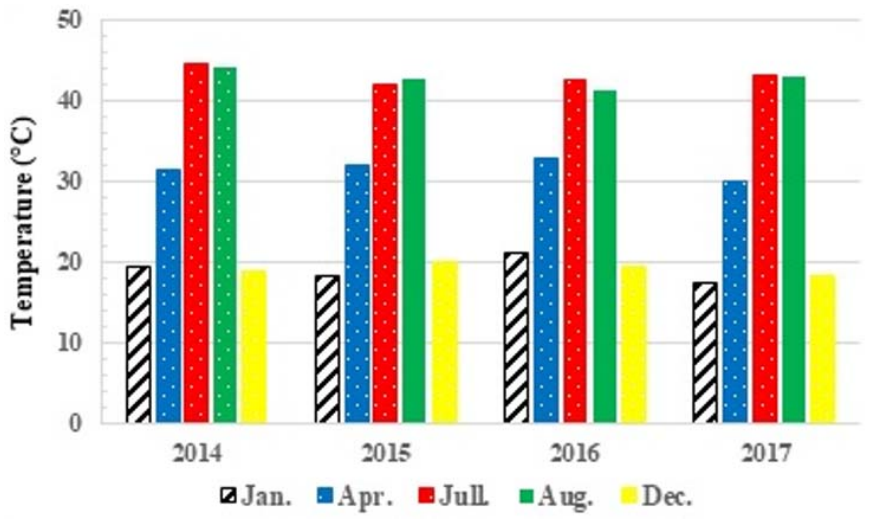

Figure 1: Ouargla weather data 2014-2017 [10]

The most common solution to overcome this problem is the addition of polymers to the base bitumen to adapt its mechanical and rheological characteristics to the environmental constraints of climate and traffic as recommended by several authors $[2,8,11,12]$.

To meet these constraints and to achieve better mechanical and rheological performance, it has become essential to switch to modified bitumen that has the advantage of being available and inexpensive as mentioned by many others $[13,14,15,16]$. One of the most common categories of bitumen modifiers is polymeric materials [17,18]. Among these polymers, elastomers, and thermoplastics, due to their ability to enhance overall viscoelastic properties of bitumen, have a great impact on bitumen characteristics and their resistance to distresses [19].

Bitumens Modified with Polymers (BMPs) are bitumen binders whose properties are modified by the addition of a chemical agent. When the latter is introduced into the basic bitumen, modifies its chemical structure and the physical and mechanical structures $[19,20,21]$. They are generally used in the road sector.

This modification of bitumen is done exclusively using polymers, which are macromolecules synthesized through a chemical reaction between smaller molecules (monomers) to form long chains. The physical properties of the resulting polymer are determined by the chemical structure of the monomers and by their sequence inside the polymer [22,23].

Currently, the growing development and use of polymer materials in construction roads are observed [24,25]. In America and Europe, BMP is commonly used; however, in Algeria, using BMP dates back to ten years ago with the construction of the east-west highway. 
The modification of the bitumen by the polymer can be carried out according to two ways; by the so-called dry method, in which the polymer introduced is considered as an aggregate during mixing, or by the wet method, which consists in modifying the bitumen structure by the polymer before the operation of mixing with the aggregates. This last method is the most effective; it is adopted in the present study.

To demonstrate the influence of this polymer, two dosages were tested; $5.0 \%$ (highly modified bitumen) and $7.5 \%$ (hyper modified bitumen). The viscosity of the modified bitumen is studied, in addition to other performances such as elasticity, plasticity index, and storage capacity.

The present study constitutes a first experiment in characterizing of bitumen modified with a polymer of the StyreneButadiene-Styrene (SBS) elastomer type produced by the company Kraton Corporation and intended for the road section D0234 (south of Algeria).

\section{MATERIALS AND METHODS}

he main materials used for this study are aggregates, bitumen and polymer in the form of granules. All the properties of the materials used were measured for the prior analysis. Other tests were carried out to measure their properties.

\section{Asphalt cement}

The asphalt cement used in this study was the bitumen 35/50 penetration grade obtained from the Naftal refinery in Alger, Algeria. It is the most used bitumen.

The identification tests carried out on bitumen are as follows:

- Penetration test EN-1426: which is an empirical method to measure the consistency of the bitumen. Penetration is defined as the distance a standard needle loaded with a $100 \mathrm{~g}$ weight will penetrate a bitumen sample for $5 \mathrm{sec}$ at $25^{\circ} \mathrm{C}$ [26].

The penetration grade of the bitumen without and with SBS was investigating using the penetrometer in accordance with EN 1426 specification, The device used is shown in Fig.2.

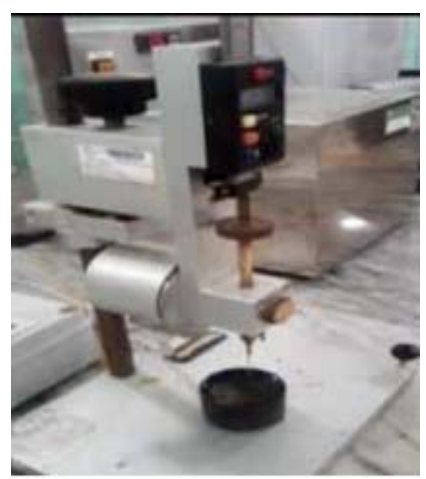

Figure 2: Penetration test apparatu.

- Softening point EN-1427: it represents the temperature at which a material softens beyond some arbitrary softness. A ring and ball apparatus are used for the determination of the softening point of bituminous materials [12,27] The basic properties of this grade of the asphalt binder are given in Tab. 1.

\section{Modifier}

The modifier selected for the present study is the most used SBS polymer in bitumen modification. It confers to bitumen its properties of elasticity, creep stability, and durability. The used SBS polymer is called D0243 E, it comes in granules of millimeter dimensions and it was supplied by Kraton Polymers International Ltd. Tab. 2 gives its physical properties.

\section{Sample preparation}

As mentioned previously, two types of bitumen modified at 5.0 and $7.5 \%$ (by weight of base asphalt) with the SBS polymer were produced; BMP5.0 and BMP7.5 [28]. Fig. 3 shows the pure bitumen modification device. 


\begin{tabular}{lcc}
\hline Test & Standard & Value \\
\hline Penetration at $25^{\circ} \mathrm{C}, 0.1(\mathrm{~mm}$ & $\mathrm{EN}-1426$ & 37.9 \\
Softening Point, ${ }^{\circ} \mathrm{C}$ & $\mathrm{EN}-1427$ & 50.5 \\
Specific Gravity & $\mathrm{EN}-1526$ & 1.01 \\
Flash Point & $\mathrm{EN}-12591$ & 335 \\
Penetration index Pfeiffer & - & -1.7 \\
PI LCPC $^{*}$ & - & 2.320 \\
\hline
\end{tabular}

Table 1: Basic characteristics of the 35/50 pen bitumen grade used [28]. *LCPC: Laboratoire des Travaux Publics du Sud, Ouargla (Algeria).

\begin{tabular}{lcc}
\hline \multicolumn{1}{c}{ Propriety } & Test Method & Result \\
Polystyrene content $(\%)$ & KM 93 & - \\
$300 \%$ Modulus $(\mathrm{MPa})$ & ISO 37 & 1.0 \\
Tensile Strength $(\mathrm{MPa})$ & ISO 37 & 2.0 \\
Specific gravity & ISO 2781 & 0.94 \\
Hardness, Shore A $(10 \mathrm{sec})$ & ISO 868 & 79.0 \\
\hline
\end{tabular}

Table 2: Physical characteristics of Kraton D0243 E Polymer used.

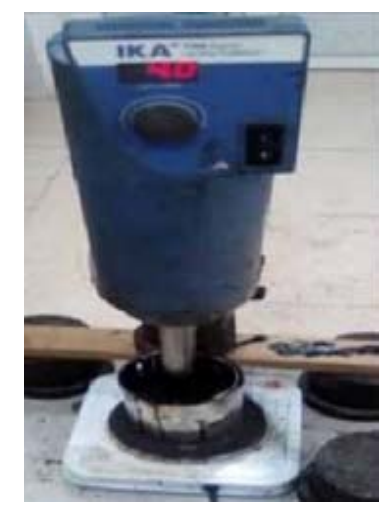

Figure 3: Bitumen modifier apparatus.

\section{Modification process:}

The bitumen-polymer mixing phase is critical and largely determines the success of the mixing, for this purpose special attention must be paid during all modification phases. The temperature, time and speed of mixing were chosen based on previous studies established by the researchers [12,28,29,30,31].

Used equipment:

- electric propeller agitator (rotation speed $=2000 \mathrm{rpm}$ ),

- adjustable heating plate,

\section{Modification steeps:}

$$
\text { - digital thermometer. }
$$

1. preheat bitumen in the oven at $140{ }^{\circ} \mathrm{C}$ for 4 hours.

2. placement of bitumen on the fitted heating plate (constant temperature).

3. switching on the mixer at a speed of $2000 \mathrm{rpm}$.

4. addition of the polymer during mixing for $1 \mathrm{~h}$ until complete dissolution at $180^{\circ} \mathrm{C}$.

5. reducing of the speed's mix to $500 \mathrm{rpm}$ for $2 \mathrm{~h}$ (Maturation phase).

6. end mixing by ensuring homogeneity. 
The degree of dispersion of the polymer in the bituminous phase is shown by its microscopic structure in Fig. 4, with the use of Fluorescence Microscopy Scanning (FMS) by simulated UV light. This technique gives the color contrast between the bitumen (no fluorescence) and the polymer used (greenish-yellow fluorescence). The fluorescent images show a change in the morphology of the PMBs as the polymer content increases.

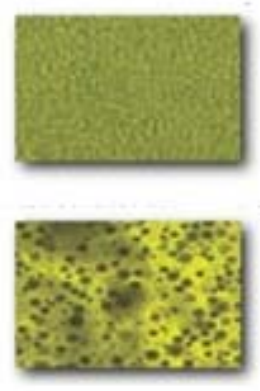

$5.0 \%$

Figure 4: Fluorescent images of SBS modified bitumen.

These two types of modified bitumen were subjected to the following tests:

- Dynamic Mechanical Analysis,

- Viscosity,

- Storage stability.

a) Dynamic Mechanical Analysis: (abbreviated DMA, also known as dynamic mechanical spectroscopy) is a technique used to study and characterize materials particularly polymers by studying their viscoelastic properties. For this purpose, a sinusoidal force (stress $\sigma$ ) is applied to a material and the resulting displacement (strain) is measured according to the EN ISO 6721 standard.

The dynamic mechanical analysis (DMA) was carried out at the LEEGO Research laboratory (USTHB univ. Algiers) using a Metravib DMA type device manufactured by Dynatest as shown in Fig. 5.

The samples were subjected to a frequency sweep between 1 and $10 \mathrm{~Hz}$, at a temperature of $30^{\circ} \mathrm{C}$. After conservation of the cylindrical specimen $\varnothing 10 \times \mathrm{H} 20 \mathrm{~mm}$ for $30 \mathrm{~min}$, the shear module || $\mathrm{G}^{*}||$ was measured by pull-compression over a frequency range of 1 to $10 \mathrm{~Hz}$.

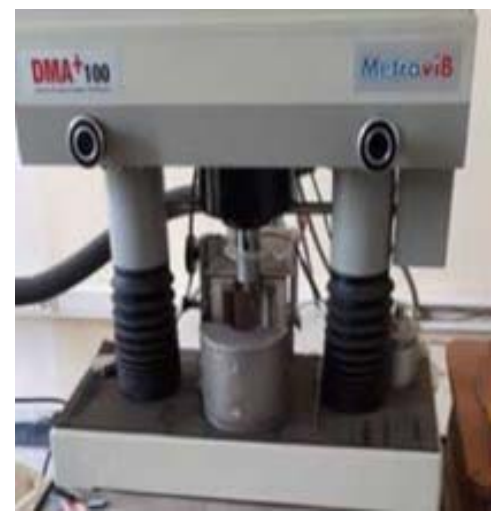

Figure 5: Metravib Apparatus used

b) Viscosity (EN13302-2010): The Brookfield viscometer developed by AMTEK was used, which makes it possible to measure the Newtonian viscosity of the bitumen by measuring the speed of rotation and the torque applied following the application of shear stress [32].

c) Storage Stability (EN13399): This test consists in measuring the softening temperature of the lower and upper parts of the bitumen samples subjected to storage conditions, after homogeneous dispersion of the polymer in the modified bitumen [33]. 


\section{RESULTS AND DISCUSSION}

$\mathrm{F}$ ig. 6 shows the evolution of the penetration considering the usual temperatures.

According to Fig. 6, it can be seen that the addition of the polymer to the bitumens increases its performances almost linearly; the modified bitumens become harder and less sensitive to temperature, this is in agreement with several author's conclusions $[34,35,36]$. The penetration decreases by $39 \%$ and $41 \%$ respectively when 5.0 and $7.5 \%$ of a polymer are added.

In this case, a certain superposition of the curves is recorded in the interval $20-25^{\circ} \mathrm{C}$. Beyond that, the sensitivity of BMP7.5 bitumen is more important.

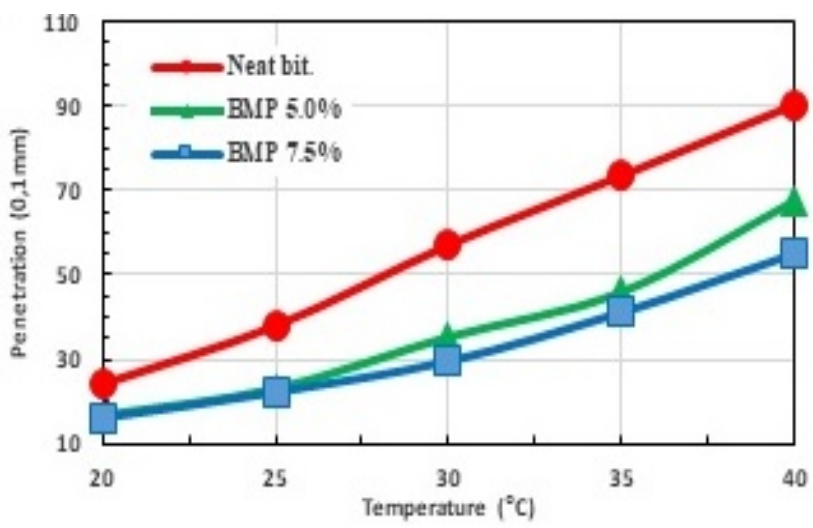

Figure 6: Penetration results according to the temperature

Likewise, it is possible to relate the penetrability to the thermal susceptibility of bitumen through the penetration index (PI) in the range of temperatures studied.

Penetration Index is another way of looking at the temperature susceptibility of the bitumen as described by Pfeiffer and Van Doormaal [37]

Fig. 7 shows the values of the penetration index calculated by the two methods; LCPC and Pfeiffer [38] according to Eqn. 1.

$$
I P=\frac{20-500 A}{1+50 A} \quad \text { where } \quad A=\frac{\log \left(\text { pen at } 25^{\circ} C\right)-\log (800)}{25^{\circ} C-\text { Softening point }\left({ }^{\circ} C\right)}
$$

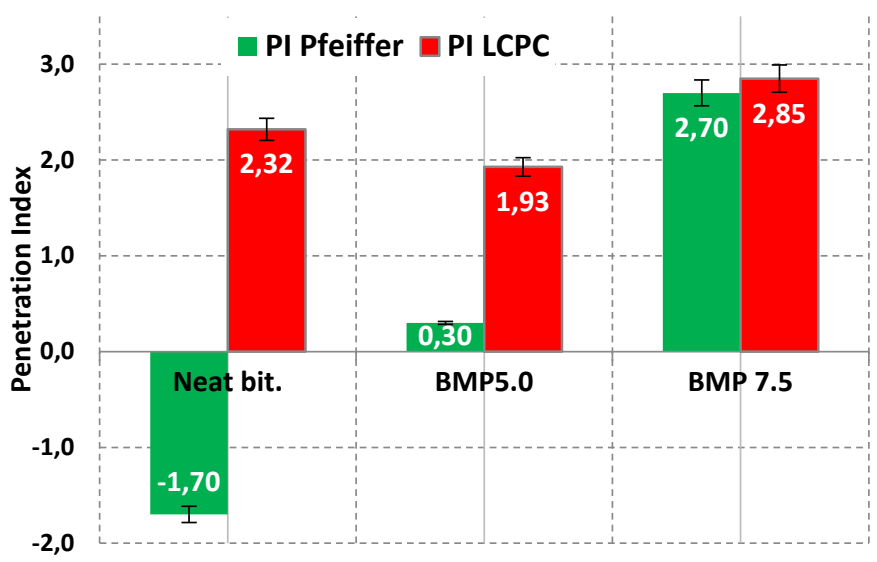

Figure 7: Bar chart showing PI values calculated by two methods. 
The penetration index represents a quantitative measure of the response of bitumen to variation in temperature. Knowing the penetration index of particular bitumen, it is possible to predict its behavior in an application.

\section{Effect of polymer on the Softening}

In order to characterize the behavior of modified bitumens at high temperatures, the softening point was determining for modified bitumen using the ring and ball test in accordance with EN 1427 specifications. The results are presented in Fig. 8.

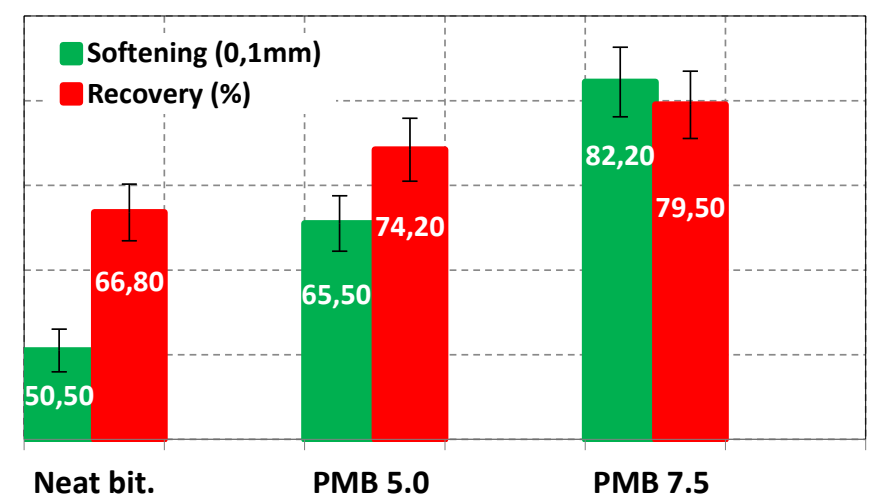

Figure 8: Bar chart showing the effect of adding polymer on penetration value and recovery

In terms of softening, a considerable change of more than $25 \%$ is recorded when changing from modified bitumen PMB5.0 to modified bitumen PMB7.5, which means that the consistency of the modified bitumens is very sensitive to the temperature.

\section{Effect of polymer on Elastic recovery \& Storage stability}

The elastic recovery is a good indicator that characterizes the ability of the binder to return to its original geometric shape following deformation.

The values show that the SBS polymer makes the bitumen more elastic and therefore it has a positive influence on the elastic return. The recovery rate in the case of $7.5 \%$ modified bitumen is around $80 \%$, which expresses very good reversibility after removal of the load.

In order to evaluate the stability and compatibility of the modifier at high temperature in asphalt binder, the storage stability test was carried out according to the EN 13399. Tab. 3 gives the results obtained. We note, also, that the difference of softening point value between the top and bottom section is less than $1.0^{\circ} \mathrm{C}$, this means that PMB is stable when stored at high temperature.

\begin{tabular}{cccc}
\hline Test & Pure bitumen & BMP 5.0 & BMP 7.5 \\
Softening Point $\left({ }^{\circ} \mathrm{C}\right)$ & 50.5 & 65.5 & 82.2 \\
Elastic recovery $(\%)$ & 66.8 & 74.2 & 79.5 \\
\hline
\end{tabular}

Table 3: Storage stability and elastic recovery results [30]

\section{Effect of polymer on dynamic viscosity}

The viscosity of the bitumen was measured using the Brookfield viscometer according to EN-13702; the equipment was used to measure the Newtonian viscosity characteristics of the polymer and modified bitumen PEN 35/50.

The sample, contained in a beaker with a cylinder, is stressed by the rotation of the RV-28 spindle. The objective is to determine the viscosity and the shear modulus of the modified bitumens.

Tab. 4 shows the results of the dynamic viscosity measured for the two types of modified bitumen (PMB5.0 and PMB7.5). 


\begin{tabular}{lccc}
\hline \multicolumn{1}{c}{ Viscosity at $135^{\circ} \mathrm{C}$} & Pure bitumen & BMP 5.0 & BMP 7.5 \\
Dynamic viscosity $(\mathrm{cP})$ & 1500 & 4500 & 9500 \\
Torsion ratio $(\%)$ & 0.30 & 0.90 & 1.90 \\
Shear Stress $(\mathrm{Pa})$ & 0.42 & 1.26 & 2.66 \\
\hline
\end{tabular}

Table 4: Rheological properties of pure and BMP.

According to Tab. 4, the dynamic viscosity of the bitumen is multiplied by 3 and 6 for the bitumen modified by 5.0 and $7.5 \%$ of the polymer, respectively. This increase is accompanied by an increase in the rate of torsion and the shear stress, which means that the modified bitumens require more stress to their mixing.

\section{Dynamic mechanical analysis}

Dynamic mechanical analysis (DMA) is a measurement where sinusoidal stress or strain is given as the input, and the strain or stress, respectively, is measured as the output (Fig. 5). Because of damping, the strain in a viscoelastic material is observed with a phase delay $\varphi$ from the stress. The stress and strain can be thus expressed as :

The results of the DMA test are presented in Fig.s 9 and 10. The test measured the stiffness modulus ||$E^{*}||$, the shear modulus ||$G^{*}||$ was obtained by the following formula.

$$
|| \mathrm{E}^{*}||=3|| \mathrm{G}^{*}||
$$

10x20mm cylindrical specimens were tested in traction-compression mode under $30^{\circ} \mathrm{C}$ at the frequencies: $1,1.58,2.51,3.98$, 6.31 , and $10 \mathrm{~Hz}$.

In Fig. 9, the values of the stiffness modulus $\mathrm{E}$ of the modified bitumen PMB7.5 are shown compared to the control bitumen, moreover, Fig. 10 represents the evolution of the shear modulus G.

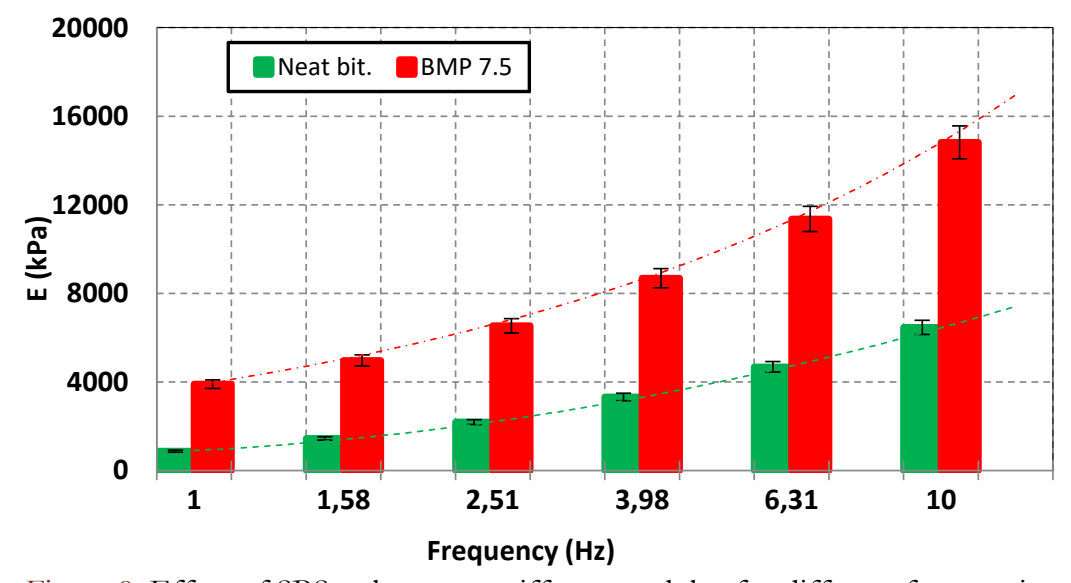

Figure 9: Effect of SBS polymer on stiffness modulus for different frequencies.

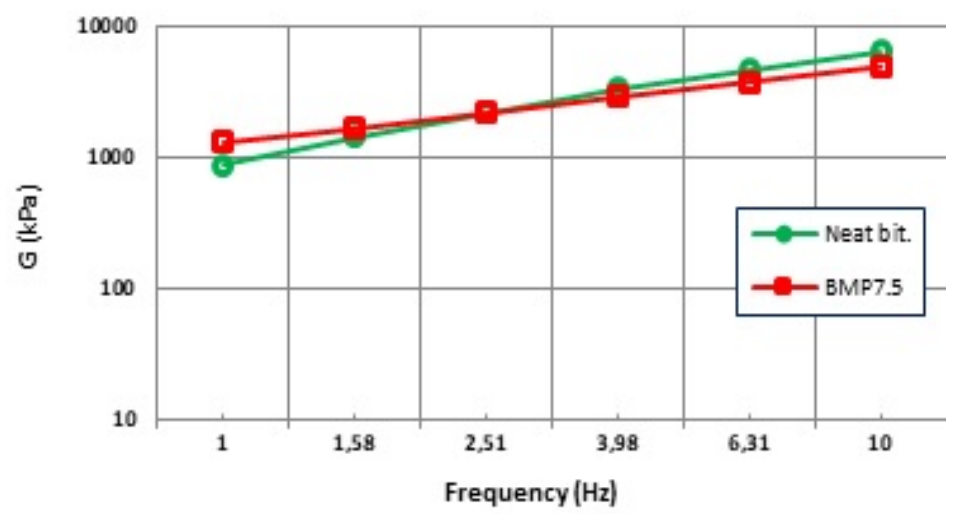

Figure 10: Effect of SBS polymer on shear modulus for different frequencies. 
According to Fig. 10, it is clear that the addition of SBS affects considerably the values of the stiffness modulus, which varies from more than $125 \%$ to $350 \%$ when moving from 1 to $10 \mathrm{~Hz}$ in frequency in the case of $7.5 \%$ modified bitumen. We also note that the evolution of the rigidity, for pure bitumen, is almost linear with the increase in frequencies. However, for the modified bitumen, the evolution is rather exponential. The equations governing the module (E) according to the frequencies ( $\mathrm{f}$ ) are given in the two cases as follows:

- Neat bitumen: $E=152.3 \mathrm{f}^{2}+42.6 \mathrm{f}+702$

- Modified bitumen: $\mathrm{E}=3937 \mathrm{e} 0.27 \mathrm{f}$

On the shear plane, the shear module G seems not to be very influenced by the SBS, since this evolution is from $49 \%$ at $1 \mathrm{~Hz}$ to $-29 \%$ at the frequency $10 \mathrm{~Hz}$. At $2.51 \mathrm{~Hz}$, the modified bitumen has the same shear modulus as the neat bitumen.

\section{CONCLUSION}

I $\mathrm{n}$ the context of improving the performance of road pavements to withstand the increasing traffic constraints and more severe climatic conditions, the present work aims to study a new bitumen improved by the Styrene-ButadieneStyrene (SBS) "Kraton Polymer". The binder is the grade 35/50 bitumen frequently used in southern Algeria.

After characterization of the used bitumen from the point of view of penetrability and softening, the emphasis is put on the rheological characteristics; viscosity and modulus of bitumen after adding 5.0 and $7.5 \%$ of this polymer.

In light of the laboratory results exposed throughout this study, the main conclusions is that the contribution of SBS in bitumen is very beneficial and acts positively on the mechanical and rheological performances of bitumen.

Indeed, in comparison with pure bitumen, bitumens after modification have the following performances:

- Bitumen modified with $7.5 \%$ of SBS has better performance in terms of thermal sensitivity with a gain in penetration and softening temperature which exceeds $60 \%$.

- Storage stability is interesting for the different SBS contents and exceeds $80 \%$ in the case of modified bitumen $7.5 \%$. On the other hand, the elastic recovery difference between the two SBS contents of the modified bitumen is relatively low.

In terms of rheological behavior, the following remakes should be made;

- The dynamic viscosity of bitumen, at $135^{\circ} \mathrm{C}$, is very sensitive to the polymer content; the viscosity is multiplied by 3 when the SBS content goes from zero (neat bitumen) to $5.0 \%$ and multiplied by 6 in the case of bitumen modified with 7.5\% SBS. To this end, Bitumen Modified with Polymers (BMPs)are a good alternative in regions with a hot climate, as is the case in the region of southern Algeria.

- The Dynamic Mechanical Analysis (DMA) tests showed that the addition of SBS increases the stiffness module significantly, while the shear moduli are little influenced.

As shown above, the stiffness modulus, according to the frequencies tested, increases almost linearly for pure bitumen and exponentially for the modified bitumen.

For the shear modulus, a slight difference is recorded between pure and modified bitumen in the range of frequencies studied. Unlike low frequencies, the shear modulus of modified bitumen is lower than that of pure bitumen. These characteristics allow modified bitumens to withstand more dynamic loads caused by road traffic.

Finally, in order to make the most of it, it is important to continue this study project, by increasing the number of rheological tests such as BBR and DSR to assess the behavior of modified bitumen under different thermal conditions.

Following the success recorded at the performance level of bitumen modified by SBS, it is important to test the asphalt mixes based on BMP, to see their behavior once put on road surfaces.

\section{ACKNOWLEDGMENTS}

$\mathrm{T}$

he authors of this article would like to express deep thanks to Mr. HADDADI Smail the head of LEGGO Laboratory for permitting carried out in his Research laboratory and Kraton Polymers International Company. 


\section{ABBREVIATIONS}

$\begin{array}{ll}\text { A: } & \text { Thermal susceptibility } \\ \text { BBR : } & \text { Bending Beam Rheometer } \\ \text { BMPs : } & \text { Bitumens Modified with Polymers } \\ \text { DMA : } & \text { Dynamic Mechanical Analysis } \\ \text { DSR : } & \text { Dynamic Shear Rheometer } \\ \text { E : } & \text { Stiffness modulus } \\ \text { FMS : } & \text { Florescent Microscopy Scanning } \\ \text { G : } & \text { Shear modulus } \\ \text { LCPC : } & \text { Laboratoire Central des Ponts et Chaussées } \\ \text { PEN : } & \text { Penetrability } \\ \text { PI : } & \text { Penetration Index } \\ \text { SBS : } & \text { Styrene-Butadiene-Styrene }\end{array}$

\section{REFERENCES}

[1] European Committee for Standardization. Bitumen and Bituminous Binders-Terminology., Belgium. EN 12597.

[2] Behzad, S. H. (2010). Bitumen Modification with Polysulphide Polymer Prepared from Heavy End Waste. Iranian Polymer Journal. (19(5), pp.363-373.

[3] Faridah, H., et al (2020). Design and optimization of polyurethane modified bitumen (PUMB) using response surface method, 2nd International Conference on Civil \& Environmental Engineering, 476, pp. 1-7. DOI:10.1088/1755-1315/476/1/012061.

[4] Gordon, A. (2002), Rheological evaluation of ethylene vinyl acetate polymer modified bitumens, Construction Building Mater, 16(8), pp. 473-487. DOI:10.1016/S0950-0618(02)00103-4

[5] Mehrdad, H., Javad, T. and Beiranvand, M. (2019). Bitumen and Its Modifier for Use in Pavement Engineering. Sustainable Construction and Building Materials, Chapter 13. pp. 249-270.

DOI: $10.5772 /$ intechopen.82489

[6] Hunter, R., Self, A., and Read, J. (2014). The shell bitumen handbook. 6 ed. Hardcover Surrey, UK

[7] Noor, Z. H., Ibrahim, Kamaruddin, M. N., and Isa M. T. (2011). Rheological Properties of Polyéthylene and Polypropylene Modified Bitumen. Word Academy of Science, International Journal of Civil and Environmental Engineering, 3(2), pp. 96-100. DOI:10.5281/zenodo.1074737.

[8] Baha, V., et al (2018). Effects of Preparation Conditions on the Properties of Crumb Rubber Modified Binder, International Journal of Architectural, Civil and Construction Sciences, 12(3), pp 289-294. DOI:10.5281/zenodo.131610710.5281/z.

[9] Porto, M., Caputo, P., et al (2019). Bitumen and Bitumen Modification: A Review on Layest Advances. Applied sciences, 9(742), pp. 1-36. DOI:10.3390/app9040742.

[10] National Office of Meteorologie (2019). Données statistiques météorologiques de la ville de Ouargla, Algeria.

[11] Strastna, J., Zanzotto, L. and Vacin O. J. (2003). Viscosity functions in polymer-modified asphalts. Journal of Colloïd Sciences, 259(1), pp. 200-207. DOI: 10.1016/s0021-9797(02)00197-2.

[12] Munera, J. C., Ossa, E. A. (2014). Polymer modified bitumen: Optimization and selection. Materials and Design, 62, pp. 91-97. DOI: 10.1016/j.matdes.2014.05.009.

[13] Ghada, S. M., Ashraf, A. R. and Talaat, A. (2021). Effect of Nanoclay Particles on the Performance of HighDensity Polyethylene-Modified Asphalt Concrete Mixture, Polymers, 13(434), pp.1-23.

DOI:10.3390/polym13030434.

[14] Jiang, Z., et al (2017). Evaluation of physical, rheological and structural properties of vulcanized EVA/SBS modified bitumen. Journal of Polymers Sciences. 134. DOI:10.1002/app.44850. 
[15] Bala, N., Napiah M., Kamaruddin, I. (2018). Effect of nanosilica particals on polypropylene polymer modified asphalt mixture performance. Case Studies in Construction Materials. 8, pp. 447-454.

DOI: 10.1016/j.cscm.2018.03.011

[16] Xinyu, Z., Shifeng W., Qiang W. and Hongru, Y. (2016). Rheological and structural evolution of SBS modified asphalts under natural weathering. Fuel 184, pp.242-247. DOI: 10.1016/j.fuel.2016.07.018

[17] Gordon, A. (2002). Rheological evaluation of ethylene vinyl acetate polymer modified bitumens. Construction and Building Materials, 16, pp. 473-487. DOI: 10.1016/S0950-0618(02)00103-4

[18] Brule, B., Brion, Y. and Tanguy, A. (1988). Paving asphalt polymer blends: relationship between composition, structure and properties. Proc AAPT, 57, pp. 41-64.

[19] Zhu, J., Birgisson, B. and Kringos, N. (2014). Polymer modification of bitumen: Advances and challenges. European Polymer Journal, 54, pp.18-38. DOI: 10.1016/j.eurpolymj.2014.02.005

[20] Word association of Roads AIPCR. (1999). Use of Modified Bituminous Binders, Special Bitumens and Bitumens with Additives in Road Pavements -technical guide-, technical committee of the flexible roads (c8), Paris.

[21] Xiaohu, L. (1997). On polymer modified road bitumens [doctoral dissertation]. Stockholm, KTH Royal Institute of Technology.

[22] Ameri, M., et al (2020). Evaluating Properties of Asphalt Mixtures Containing polymers of Styrene Butadiene Rubber (SBR) and recycled Polyethylene Terephthalate (rPET) against Failures Caused by Rutting, Moisture and Fatigue, Frattura ed Integrità Strutturale, 53, pp. 177-186. DOI: 10.3221/IGF-ESIS.53.15.

[23] Lesueur, D. (2002). Rhéologie des Bitumes: Principes et Modification. Rhéologie. 2, pp 1-30.

[24] Ramadhansyah, P. J., et al (2019). Effects of black rice husk ash on asphalt mixture under aging condition. Eart and Environment Science, 220, pp. 1-6. DOI:10.1088/1755-1315.

[25] Romastarika, R., et al (2017). Effect Of Black Rice Husk Ash On The Physical And Rheological Properties Of Bitumen. Construction and Building Materials 24, pp. 2145-2150. DOI:10.1063/1.4998383

[26] European Standards. Bitumen and bituminous binders - Determination of needle penetration. 1426:2007.

[27] European Standards. Bitumen and bituminous binders - Determination of the softening point - Ring and Ball method. 1427:2007

[28] Kebaili, N. (2015). L'asphalte caoutchouc valorisation de la poudrette de caoutchouc en domaine routier. Thèse de doctorat en génie civil, université Ouargla, 130 pp.

[29] Kebaili, N., Benabdelouahab, F. and Zerzour, A. (2013). Valorization of asphalt rubber fine powder in road field. Key Engineering Materials, 550 pp. 85-90. DOI: 10.4028/www.scientific.net/KEM.550.85

[30] Kemassi, N., Boucherba, M., and Kebaili, N. (2019). Bitumes Hautement Modifiés par Polymère (HiMA): Influence des polymères sur la viscosité des liants -Etude de cas : D0234. Mémoire de master en Génie civil, FSA. Université de Ouargla.

[31] Farazmand, P., Hayati, P., Shaker, H. and Rezaci, S. (2021). Relationship between microscopic analysis and quantitative and qualitative indicators of moisture susceptibility evaluation of warmmix asphalt mixtures containing modifiers. Frattura ed Integrità Strutturale, 51, pp.215-224. DOI: 10.3221/IGF-ESIS.51.17

[32] European Standards. Bitumen and bituminous binders - Determination of dynamic viscosity of bituminous binder using a rotating spindle apparatus 13302:2010

[33] European Standards. Bitumen and bituminous binders - Determination of storage stability of modified bitumen 13399:2018

[34] Damadi, S. M., Edrisi, A., Fakhri, M., Rezaei, S. and Worya, M. K. (2020). Fatigue Analysis of Bitumen Modified with Composite of Nano-SiO2 and Styrene Butadiene Styrene Polymer. Frattura ed Integrità Strutturale, 53, pp.202-209. DOI: 10.3221/IGF-ESIS.53.17

[35] Ming, L., et al (2015). Thermo-rhological behavior and compatibility of modified asphalt with various styrenebutadiene structures in SBS copolymers. Materials and Design, 88, pp.177-185.

DOI:10.1016/j.matdes.2015.09.002

[36] Karakas, A. S., Kuloglu, N., Kök, B. V. and Yilmaz, M. (2015). The evaluation of the field performance of the neat and SBS modified hot mixture asphalt. Construction and Building Materials, 98, pp. 678-684. DOI: $10.1016 /$ j.conbuildmat.2015.08.140. 
[37] Olugbenga, A. E., Olugbenga, A. F., and Jonathan, G. (2012). Softening point and Penetration Index of bitumen from parts of Southwestern Nigeria. Nafta zaghreb, 63 (9-10), Pp. 319-323.

[38] Boucherba, M., Kriker, A., and Kebaili, N. (2017). The valorization of the plastic waste to the rheological characteristics of bituminous mixtures. AIP Conference Proceeding, 1814, pp. 1-11. DOI: 10.10631/1.4976244. 